\title{
Desempenho de ovelhas Santa Inês manejadas a pasto e suplementadas com gordura protegida no pós-parto
}

\author{
Performance of Santa Inês sheep managed to pasture and supplemented with protected fat postpartum
}

\section{Marcos Paulo dos Santos* e Marcelo Marcondes de Godoy}

Recebido em 10/09/2016 / Aceito em 11/01/2017

\section{RESUMO}

Objetivou-se avaliar o efeito da suplementação com sabões de cálcio de ácidos graxos (SCAG) no desempenho produtivo e reprodutivo de animais mantidos à pasto. $\mathrm{O}$ experimento foi realizado no setor de ovinocultura do IF Goiano - Campus Ceres (GO). Após a sincronização de estro e cobertura, 32 ovelhas da raça Santa Inês foram escolhidas aleatoriamente ao número de partos e distribuídas de acordo com o escore de condição corporal (ECC) e ordem de parto em quatro tratamentos: (TEST - sem suplementação concentrada; SUPL - suplemento concentrado sem a inclusão SCAG; GORD5 suplemento concentrado com a inclusão de $5,0 \%$ de SCAG e; GORD10 - suplemento concentrado com a inclusão de 10,0\% SCAG). As matrizes foram mantidas em pastagem de capim Tanzânia (Panicum maximum) e a suplementação teve início no primeiro dia pós-parto sendo mantida até os 60 dias pós-parto (DPP). Foram avaliados o peso corporal (PC) e o ECC de todas as ovelhas, a cada 15 dias. Aos 60 dias experimentais avaliou-se a porcentagem de ovelhas que manifestaram estro e o intervalo parto primeiro estro (IPPE) das matrizes. A outra fase do estado constou da avaliação do ganho médio diário (GMD) e do PC dos cordeiros desde o parto até 60 dias de idade. Não houve influência da suplementação com ou sem SCAG ( $>>0,05)$ sobre o PC, ECC das ovelhas, e no PC e GMD dos cordeiros. A porcentagem de manifestação de estro não foi influenciada pelas dietas experimentais. A suplementação concentrada sem inclusão de SCAG até os 60 dpp reduz o IPPE, enquanto, a inclusão de SCAG não promove melhoria no desempenho produtivo e reprodutivo de ovelhas Santa Inês manejadas a pasto.
PALAVRAS-CHAVE: ganho médio diário, nutrição, ovinos, Panicum maximum.

\section{ABSTRACT}

The objective was to evaluate the effect of supplementation with calcium soaps of fatty acids (SCAF) in the productive and reproductive performance of animals kept at pasture. The experiment was conducted in sheep breeding sector of IF Goiano - Campus Ceres (GO). After synchronization of estrus and coverage, 32 Santa Ines sheep were randomly chosen by birth order and according with the body condition score (BCS) in four treatments: (TEST - without concentrate supplementation; SUPL - concentrated supplement without including SCAF; GORD5 - concentrated supplement with including $5.0 \%$ of SCAF and; GORD10 - concentrated supplement with the inclusion of $10.0 \%$ SCAF). The arrays were kept in Tanzania pasture (Panicum maximum) and supplementation began on the first day postpartum and was maintained through 60 days postpartum (dpp). They assessed the body weight (BW) and BCS of all sheep every 15 days. After 60 days trial the percentage of sheep who have expressed estrus and first estrus birth interval (IBFE) of matrices were evaluated. The other phase of the study consisted of the evaluation of the medium daily gain (MDG) and $\mathrm{BW}$ of lambs from birth to 60 days old. There was no effect of supplementation with or without SCAF $(p>0.05)$ on the BW, BCS sheep and BW and MDG of lambs. The percentage of estrus was not influenced by experimental diets. The supplementation concentrate without inclusion of SCAF to $60 \mathrm{dpp}$ reduces IBFE, while the inclusion of SCAF does not promote improvement in the productive and reproductive performance of Santa Ines grazing managed sheep.

\footnotetext{
${ }^{1}$ Universidade Federal de Goiás, Goiânia, GO, Brasil.

${ }^{2}$ Instituto Federal Goiano, Ceres, GO, Brasil.

*Autor para correspondência <marcospaulo_agronomo@hotmail.com>
} 
KEYWORDS: medium daily gain, nutrition, sheep, Panicum maximum.

\section{INTRODUÇÃO}

O consumo de suplemento por ovelhas mantidas a pasto favorece maior ingestão de nutrientes e, consequentemente, melhora o desempenho produtivo e reprodutivo, visto que a forrageira nem sempre atende plenamente as exigências nutricionais dos animais, principalmente, no período gestaçãolactação, considerado o mais crítico no sistema de produção (ROSA et al. 2007).

Ovelhas suplementadas no período pré-parto, em especial, no terço final da gestação parem e desmamam cordeiros mais pesados. Além disso, mantêm o peso durante a lactação (ROSA et al. 2007), o que justifica a suplementação nos 30 dias anteriores ao parto, quando as exigências de ovelhas gestantes são altas e não podem ser atendidas pela ingestão exclusiva de pastagem. Quando a suplementação é prolongada para o período pós-parto observamse ainda ganhos consideráveis no peso corporal, incrementos no escore de condição corporal (ECC) e maiores porcentagens de fertilidade no rebanho (ROSA et al. 2007, NOGUEIRA et al. 2009).

Uma das formas de atender as exigências nutricionais dos animais nesta fase é a adição de maiores quantidades de carboidratos solúveis na dieta. Entretanto, essa prática pode comprometer a ingestão de fibras, além de aumentar a acidez do rúmen, causando distúrbios metabólicos (VALINOTE et al. 2006). Por outro lado, a inclusão de lipídeos na dieta de ruminantes é uma alternativa para evitar esses efeitos, podendo ainda influenciar positivamente o ganho de peso, visto que os lipídeos contribuem para o aumento de energia disponível a ser metabolizada e convertida em massa corporal pelos animais, melhorando o balanço energético (MATTOS et al. 2000).

A gordura protegida consiste em uma fonte de ácidos graxos linoléico e linolênico que será absorvida diretamente no intestino. Os ácidos graxos insaturados, presentes na dieta, principalmente nos produtos vegetais oleaginosos, por exemplo, na soja e no caroço de algodão, são convertidos no rúmen em ácidos graxos saturados, como o esteárico. Os ácidos graxos da gordura protegida passam intactos pelo rúmen, e quando absorvidos no intestino delgado, são usados no metabolismo animal (AFERRI 2003).
A utilização de ácidos graxos na dieta de ruminantes, além de ser uma ferramenta para melhoria dos parâmetros produtivos como peso e escore de condição corporal, também pode ser utilizada para aumentar a eficiência reprodutiva dos animais (GRESSLER \& SOUZA 2009), devido ao aumento da pulsatilidade do hormônio LH e crescimento do folículo préovulatório (SARTORI \& GUARDIEIRO 2010).

Diante do exposto objetivou-se avaliar a influência da inclusão de sabão de cálcio de ácidos graxos (SCAG) na dieta, sobre o desempenho produtivo e reprodutivo das ovelhas no período pósparto e sobre o desempenho produtivo dos cordeiros.

\section{MATERIAL E MÉTODOS}

O experimento foi realizado nos meses de maio e junho de 2012 no setor de ovinocultura, no Campus Ceres, do Instituto Federal Goiano. Foram utilizadas 63 ovelhas, primíparas e multíparas, da raça Santa Inês, que passaram por exame clínico geral e ginecológico e quando houve necessidade, foram vermifugadas e tratadas de eventuais enfermidades. Os animais foram manejados a pasto com sal mineral e água à vontade.

Previamente à cobertura, os reprodutores foram avaliados clinicamente e andrologicamente. Para a cobertura foram utilizados três reprodutores da raça Santa Inês na proporção de um macho para 20 fêmeas, em sistema de rodízio. Previamente ao início do estudo, as ovelhas foram submetidas à sincronização de estro por meio da aplicação intramuscular de duas doses de 0,263 mg de cloprostenol sódico (Sincrocio, Laboratório Ouro Fino) em intervalos de 11 dias para concentrar a parição das mesmas. Todas as ovelhas foram cobertas através de monta natural controlada, para que os partos se concentrassem em um mesmo período do ano.

Após o parto, selecionou-se 32 ovelhas que foram distribuídas uniformemente de acordo com o escore de condição corporal (ECC), idade e ordem de parto, em quatro tratamentos: TEST - sem suplementação concentrada; SUPL - suplemento concentrado sem a inclusão de sabões de cálcio de ácidos graxos (SCAG); GORD5 - suplemento concentrado com a inclusão de 5,0\% de SCAG e; GORD10 - suplemento concentrado com a inclusão de $10,0 \%$ SCAG.

No período experimental, durante o dia, os animais dos quatro tratamentos foram mantidos 
agrupados em piquetes formados com capim Tanzânia (Panicum maximum). No final da tarde, esses foram separados em lotes, nos respectivos tratamentos, os quais recebiam a suplementação e permaneciam por toda à noite para ingestão do concentrado e amamentação de seus respectivos cordeiros. $\mathrm{Na}$ manhã do dia seguinte, reagrupavam-se os animais para pastejo.

A pastagem de capim Tanzânia possuía valores bromatológicos de $22 \%$ de matéria seca (MS), $9,92 \%$ de Proteína bruta (PB), $0,14 \%$ de cálcio (Ca), $0,20 \%$ de fósforo (P) e $60,72 \%$ de fibra em detergente neutro (FDN). Os suplementos dos lotes de ovelhas suplementadas foram balanceados (Tabela 1) de acordo com o AFRC (1993). A quantidade de suplemento fornecido foi ajustada de forma que as ovelhas de cada lote suplementado tivessem acesso ao mesmo consumo de energia metabolizável (EM) e PB. O suplemento foi composto basicamente por milho em grão triturado e farelo de soja, com o uso do MEGALAC-E ${ }^{\circledR}$ como fonte de ácidos graxos poliinsaturados (gordura protegida). $\mathrm{O}$ fornecimento do suplemento concentrado foi fixado em torno de $0,50 \%$ do peso corporal (PC), para evitar possível efeito substitutivo da dieta, desde o parto até 60 dias pós-parto. Quinze dias, previamente, ao início do experimento forneceu-se apenas $50 \%$ da quantidade de suplemento preconizada, para adaptação à dieta experimental e manejo alimentar. No período experimental, todos os cordeiros tiveram acesso à silagem e suplemento concentrado à vontade durante o dia.

Tabela 1 - Composição dos suplementos concentrados.

Table 1 - Composition of concentrate supplements.

\begin{tabular}{|c|c|c|c|}
\hline \multirow[t]{2}{*}{ Ingredientes do suplemento } & \multicolumn{3}{|c|}{$\%$} \\
\hline & SUPL & GORD 5 & GORD 10 \\
\hline Milho, grão moído & 27,35 & 20,63 & 13,99 \\
\hline Farelo de soja & 65,00 & 65,00 & 65,00 \\
\hline Megalac $\mathrm{E}^{\circledR}$ & 0,00 & 5,00 & 10,00 \\
\hline Uréia & 2,50 & 3,92 & 5,36 \\
\hline Sal mineralizado ${ }^{1}$ & 5,00 & 5,30 & 5,50 \\
\hline \multirow[t]{2}{*}{ Monensina sódica 5\% } & 0,150 & 0,150 & 0,150 \\
\hline & \multicolumn{3}{|c|}{ Composição (\% na MS) } \\
\hline Proteína bruta & 39,23 & 42,40 & 45,57 \\
\hline Nutrientes digestíveis totais (NDT) & 85,92 & 89,32 & 92,14 \\
\hline $\mathrm{Ca}$ & 2,85 & 2,87 & 2,86 \\
\hline \multirow[t]{2}{*}{$P$} & 1,37 & 1,31 & 1,24 \\
\hline & \multicolumn{3}{|c|}{ Quantidade por ovelha, g } \\
\hline Suplemento concentrado & 300 & 270 & 245 \\
\hline Consumo PB & 231,5 & 231,5 & 231,5 \\
\hline Gordura protegida & - & 13,5 & 24,5 \\
\hline \multirow[t]{3}{*}{ Concentrado: Gordura ${ }^{2}$} & - & 2,22 & 2,24 \\
\hline & \multicolumn{3}{|c|}{ Consumo de EM, $\mathrm{MJ} / \mathrm{dia}^{3}$} \\
\hline & 16,72 & 16,73 & 16,74 \\
\hline
\end{tabular}

${ }^{\mathrm{I}}$ Guabiphos Ovinos $\mathrm{AE}^{\circledR}$ : cálcio: $140 \mathrm{~g}$; fósforo: $65 \mathrm{~g}$; magnésio: $10 \mathrm{~g}$; sódio $130 \mathrm{~g}$; cobalto: $80 \mathrm{mg}$; ferro: $1000 \mathrm{mg}$; iodo: $60 \mathrm{mg}$; manganês: $3000 \mathrm{mg}$; selênio: $10 \mathrm{mg}$; zinco: $5000 \mathrm{mg}$; vitamina A: $50000 \mathrm{UI}$; vitamina E: 312 UI. ${ }^{2}$ Relação de substituição de concentrado do SUPL por gordura protegida no GORD5 e GORD10. ${ }^{3}$ Estimado segundo o AFRC (1993). 
Após o parto, a detecção de estro foi verificada diariamente com auxílio de quatro rufiões marcados com tinta na região do peito, para que no momento do salto ocorresse o tingimento da garupa da fêmea. Posteriormente, o animal tingido e identificado foi submetido à confirmação quanto à manifestação do estro, averiguando-se os sintomas típicos de animais em estro.

Realizou-se a pesagem das ovelhas e dos cordeiros e avaliação do ECC, das ovelhas, a cada 15 dias, desde o parto até 60 dias pós-parto. O ECC foi realizado segundo metodologia descrita por CALDEIRA \& VAZ PORTUGAL (1998), atribuindo valores de 1 a 5 , em que 1 corresponde a animal muito magro e 5 a animal obeso.

Utilizou-se o delineamento inteiramente casualizado e as análises estatísticas foram realizadas com o auxílio do software SAEG 9.0 (RIBEIRO JÚNIOR \& MELO 2009). Foram analisadas as características de desempenho produtivo (peso e ganho de peso diário dos cordeiros e ovelhas, e escore de condição corporal das ovelhas) e reprodutivo (\% ovelhas em estro até os 60 dias pós-parto e intervalo parto primeiro estro). Análises de regressões foram ajustadas para o desempenho produtivo das ovelhas e dos cordeiros ao longo do tempo. A performance reprodutiva das ovelhas ao final do período experimental foi comparada pelo teste Tukey ao nível de $5 \%$ de significância.

\section{RESULTADOS E DISCUSSÃO}

As dietas experimentais não influenciaram $(p>0,05)$ o peso corporal dos animais. Durante o período compreendido entre o parto até 60 dias pós-parto, observou-se perda de peso das ovelhas, sendo esta da ordem de 3,88 $\pm 0,29 \mathrm{~kg}$ (Figura 1). A perda de peso em ovelhas lactantes é comum e deve-se a dificuldade de fornecimento de nutrientes pela alimentação em quantidades adequadas para as matrizes. Nesta fase, a demanda energética aumenta mais rapidamente que o consumo de matéria seca, assim a ovelha deve usar as reservas energéticas para a produção de leite, deixando dessa forma, de acumular massa corporal (ARAÚJO et al. 2008).

O escore de condição corporal (ECC) das ovelhas não variou significativamente ao longo do tempo em ambos os tratamentos analisados (Figura 2). Resultados similares foram observados também por NEGRI et al. (2014). Já AFONSO et al. (2010) verificaram melhoria no ECC de ovelhas suplementadas com gordura protegida (GP) no terço final da gestação. A condição corporal, estado visual da deposição de gordura nos tecidos, reflete o acúmulo e/ou a perda de peso que ocorre durante determinada fase da vida do animal. Assim, a similaridade no peso corporal das ovelhas entre as dietas experimentais desde o parto até os 60 dias pós-parto foi fator limitante para que a ocorrência de melhorias na condição corporal dos animais não fosse detectada neste estudo.

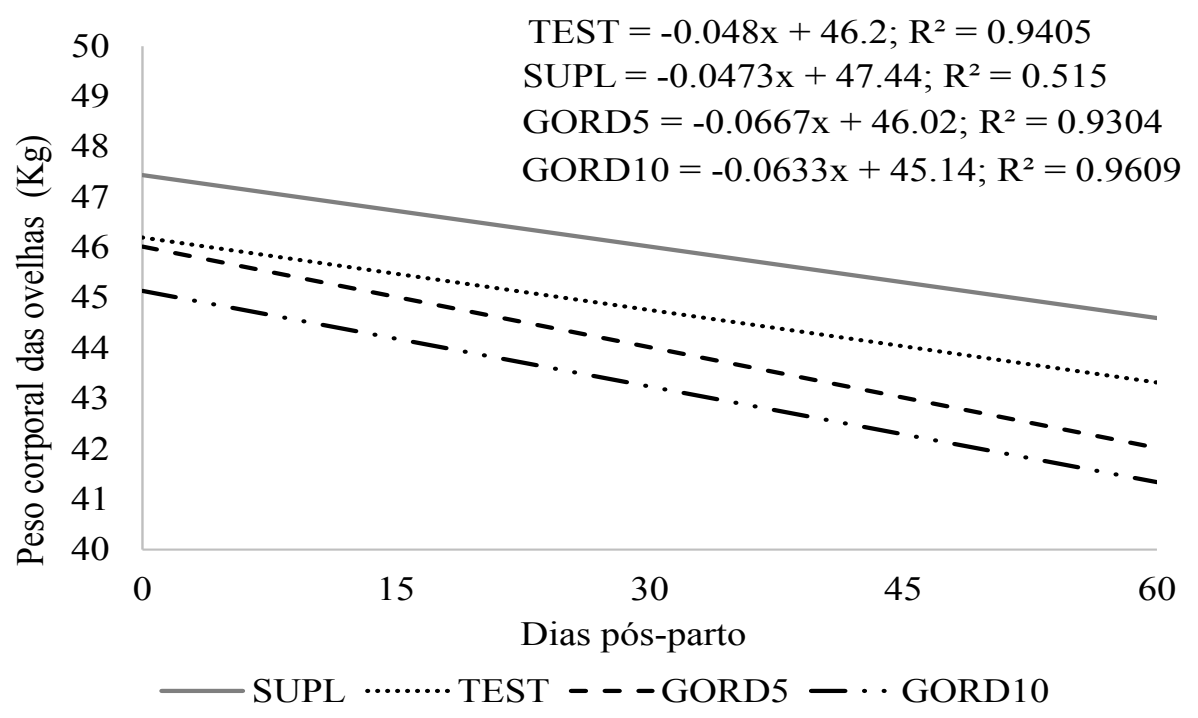

Figura 1 - Peso Corporal de ovelhas Santa Inês em intervalos quinzenais do parto até 60 dias pós-parto. Figure 1 - Body Weight of Santa Inês sheep in fortnightly intervals from calving to 60 days postpartum. 
A ausência de melhorias no desempenho produtivo das ovelhas sugere que a suplementação concentrada com ou sem a inclusão de SCAG não tenha sido capaz de estimular o consumo de forragem. Somada a isto, a má qualidade bromatológica da forrageira no período do ano em que o experimento foi realizado (transição chuvas-seca) pode ter limitado $\mathrm{o}$ aporte dos nutrientes, mesmo com prolongado tempo de pastejo, comprometendo dessa forma o desempenho das ovelhas (Figuras 1 e 2).

$\mathrm{O}$ uso de gordura protegida (GP) na dieta não promoveu melhora $(\mathrm{p}>0,05)$ no desempenho produtivo das ovelhas. EMEDIATO et al. (2009) também não verificaram influência da dieta contendo GP no peso corporal desde o parto até o desmame dos cordeiros em ovelhas Bergamácia. Resultados contraditórios aos do nosso estudo são encontrados em BONA et al. (1994). A razão da GP não ter proporcionado melhoria no desempenho das ovelhas deve-se a sua dinâmica e assimilação no metabolismo animal. Quando os ácidos graxos da GP se ligam as lipoproteínas do fígado e alcançam a circulação, duas situações podem ocorrer. Na primeira delas, quando a quantidade de ácidos graxos consumida consegue atender a demanda energética do animal, ocorre o transporte do excesso de ácidos graxos para o tecido adiposo, sendo estes armazenados na forma de triglicerídeos, aumentando o PC e consequentemente o ECC do animal. Por outro lado, quando toda a quantidade de ácidos graxos consumida é oxidada nos tecidos periféricos para produção de energia em função do animal ainda estar em balanço energético negativo (BEN), não ocorre formação e tampouco deposição de triglicerídeos no tecido adiposo do animal (FERNANDES et al. 2012). Diante disto e com base nas escalas de ECC dos animais (Figura 2), pode-se inferir que a quantidade de ácidos graxos presentes no GORD5 e GORD10 não foi suficiente para melhorar o balanço energético dos animais em comparação aos animais suplementados sem GP e os não suplementados, o que explica a igualdade das escalas de ECC dos animais.

$\mathrm{O}$ intervalo parto primeiro estro (IPPE) foi influenciado pelas dietas experimentais, enquanto a porcentagem de estro permaneceu inalterada. A suplementação concentrada sem a inclusão de GP reduziu o intervalo parto primeiro estro comparado às demais dietas experimentais (Tabela 2). Esperava-se que nas dietas contendo GP, o IPPE fosse reduzido, pois, a GP pode aumentar a produção de prostaglandina (PGF2 $\alpha$ ) no metabolismo animal, resultando em mais rápido retorno da atividade reprodutiva da ovelha (FUNSTON 2004). Entretanto, aumentos na produção PGF2 $\alpha$ ocorrem quando os animais conseguem ter a condição corporal reestabelecida pela suplementação (SANTOS et al. 2008), o que não foi observado neste estudo.

$\mathrm{Na}$ literatura vários trabalhos reportam sobre a influência positiva do fornecimento de GP sobre a aceleração do IPPE (MATTOS et al. 2000, FUNSTON 2004, EMEDIATO et al. 2009, GRESSLER \& SOUZA 2009). Vale ressaltar que efeitos positivos da inclusão de GP na dieta sobre a reprodução poderão ocorrer, no entanto, primeiramente, a condição corporal das ovelhas deverá ser melhorada. Assim, estratégias concomitantes ao uso de GP no pósparto como: seleção prévia de matrizes com melhor condição corporal e manejo alimentar desde o início da gestação poderão contribuir para sucessos na adoção do fornecimento de GP como ferramenta no manejo nutricional na ovinocultura.

O PC e o ganho médio diário (GMD) dos cordeiros não foram influenciados $(\mathrm{p}>0,05)$ pelas dietas experimentais (Figuras 3A e 3B). Este comportamento refletiu o desempenho produtivo de suas mães, que foi similar entre as dietas. COSTA et al. (2007) reportam que o restabelecimento da ovelha no pós-parto influencia tanto na diminuição do anestro pós-parto, quanto na produção de leite da ovelha, o que permite maior aporte de leite para suas crias, acarretando em maior desempenho dos cordeiros. Além disso, ovelhas com melhor condição corporal desmamam cordeiros mais pesados (QUEIROZ et al. 2015). Isso demonstra que a condição corporal da ovelha exerce grande influência na produção de cordeiros, e que melhorias nesta proporcionam superioridade no peso ao nascimento, peso no desmame, e no ganho médio de peso diário. Assim, a similaridade no desempenho das ovelhas permite explicar o desempenho dos cordeiros, pois estes dependem do estado nutricional da mãe.

As divergências encontradas entre este estudo e a literatura sobre o desempenho de ovelhas suplementadas com gordura protegida reforçam a necessidade de estudos que analisem particularidades no sistema metabólico e reprodutivo, nas diversas raças, visando apontar caminhos mais claros para novas pesquisas, que futuramente venham solucionar as questões da baixa produtividade da ovinocultura em sistemas extensivos. 


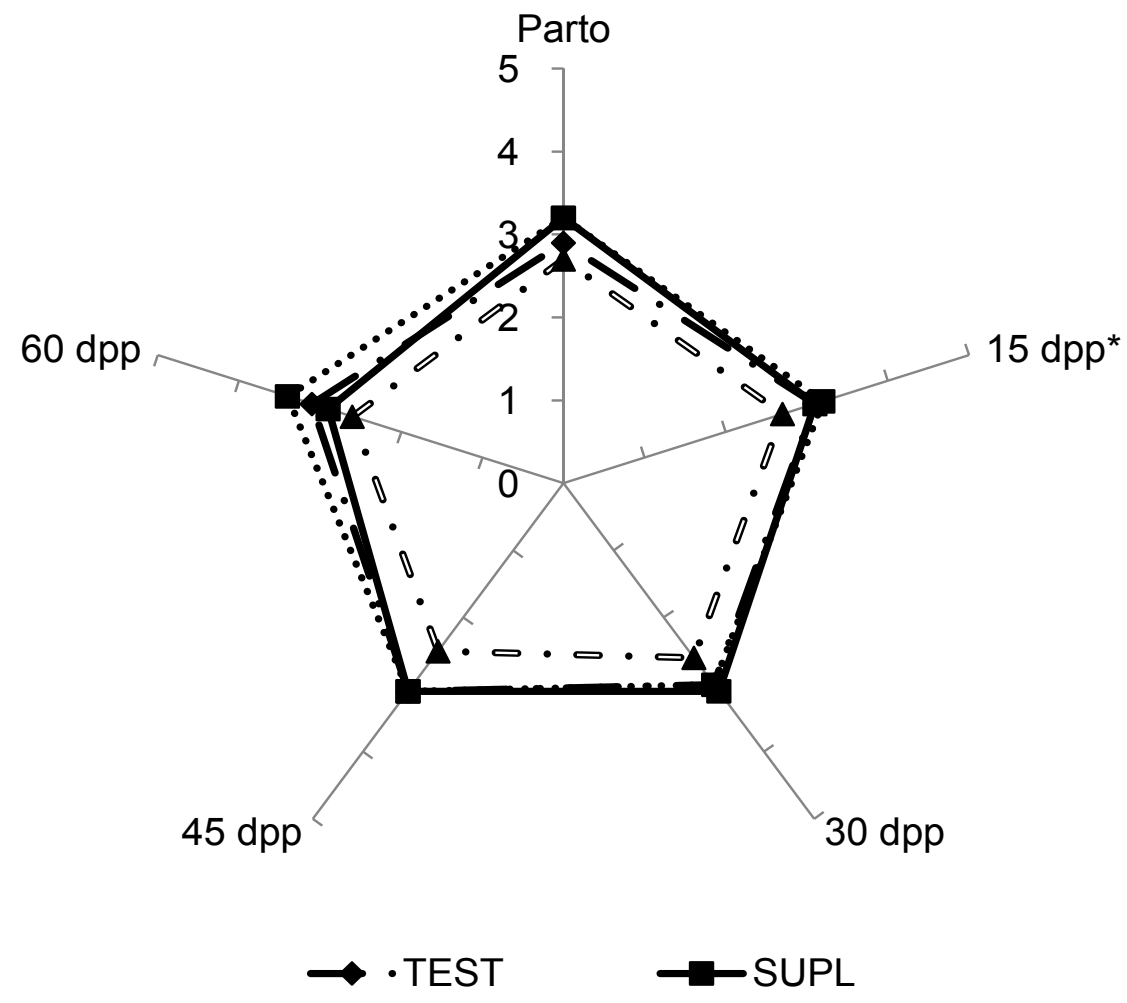

Figura 2 - Escore de Condição Corporal de ovelhas Santa Inês em intervalos quinzenais desde o parto até 60 dias pós-parto. *dpp: dias pós-parto.

Figure 2 - Body Condition Score of Santa Inês sheep in fortnightly intervals from calving to 60 days postpartum. *dpp : postpartum days

Tabela 2 - Porcentagem de animais que manifestaram estro até os 60 dias pós-parto, e intervalo entre a data do parto ao primeiro estro.

Table 2 - Percentage of animals in estrus until 60 pospartum days, and interval between the date of birth to the first estrus.

\begin{tabular}{lcc}
\hline Tratamentos & \% estro & Intervalo parto primeiro estro (dias) \\
\cline { 2 - 2 } TEST & $37,5 \pm 13,06 \mathrm{a}$ & $32 \pm 2,37 \mathrm{~b}$ \\
SUPL & $50,0 \pm 13,06 \mathrm{a}$ & $23 \pm 2,37 \mathrm{a}$ \\
GORD5 & $37,5 \pm 13,06 \mathrm{a}$ & $33 \pm 2,37 \mathrm{~b}$ \\
GORD10 & $37,5 \pm 13,06 \mathrm{a}$ & $29 \pm 2,37 \mathrm{~b}$ \\
\hline p-valor & 0,1825 & 0,001259 \\
\hline CV \% & 32,17 & 8,20
\end{tabular}

Médias seguidas de letras iguais nas colunas não diferem pelo teste Tukey ao nível de 5\%. 


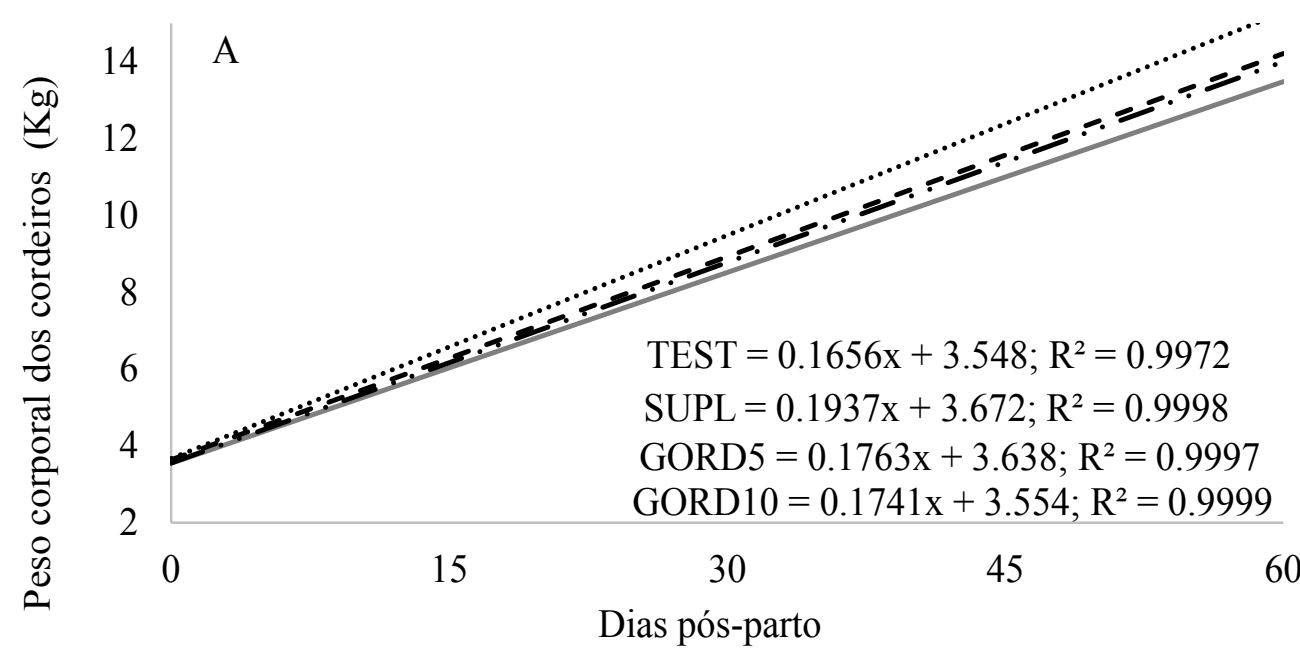

Dias pós-parto

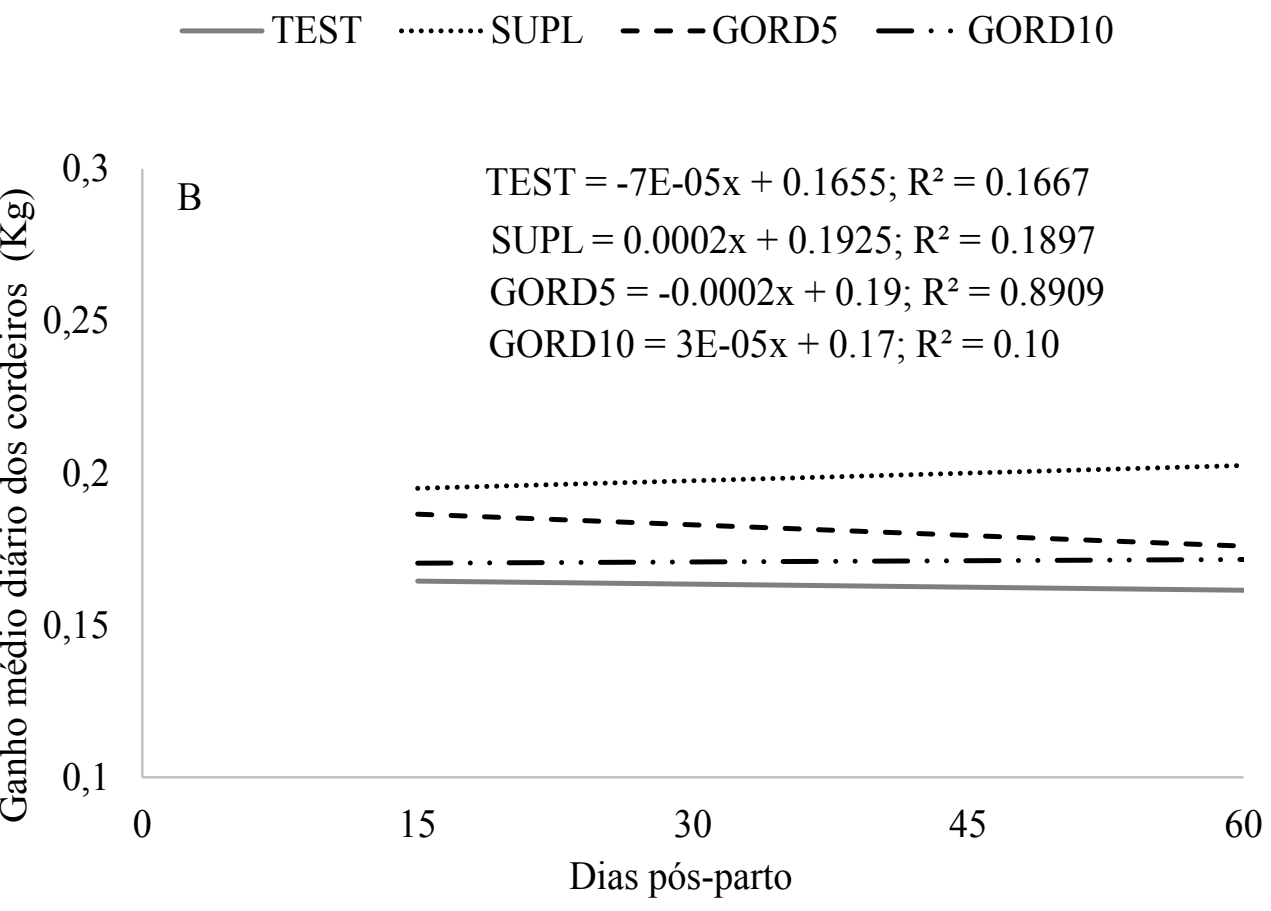

TEST …..... SUPL - - -GORD5 - - GORD10

Figura 3 - Peso Corporal (A) e Ganho Médio Diário (B) de cordeiros Santa Inês amamentados por ovelhas suplementadas no pós-parto.

Figure 3 - Body weight (A) and gain daily average (B) of Santa Ines lambs suckled by sheep supplemented on the postpartum.

\section{CONCLUSÃO}

A inclusão de GP na dieta não melhora o desempenho produtivo de ovelhas e cordeiros Santa Inês manejados em pastagens de capim Tanzânia. A suplementação concentrada sem inclusão de GP acelera o retorno de ovelhas Santa Inês, manejadas a pasto, à atividade reprodutiva.

\section{AGRADECIMENTOS}

Ao Conselho Nacional de Desenvolvimento Científico e Tecnológico (CNPq) pelo financiamento da bolsa de pesquisa.

\section{REFERÊNCIAS}

AFERRI G. 2003. Desempenho e características da carcaça de novilhas alimentadas com diferentes fontes de gordura. Dissertação (Mestrado em Zootecnia). Pirassununga: 
Universidade de São Paulo. 61p.

AFONSO VAC et al. 2010. Correlações entre padrões hematológicos, parasitológicos e desempenho animal de ovelhas suplementadas com gordura protegida. Boletim de Indústria Animal 67: 125-132.

AFRC - Agricultural And Food Reaserch Council. 1993. Energy and protein requirements of ruminants. Wallingford: CAB International. 159p.

ARAÚJO JA et al. 2008. Intoxicação experimental por Ipomoea asarifolia (Convolvulaceae) em caprinos e ovinos. Pesquisa Veterinária Brasileira 28: 488-494.

BONA FA et al. 1994. Efeitos da utilização de diferentes níveis de sais cálcicos de ácidos graxos no desempenho de ovelhas no pós-parto. Revista do Setor de Ciências Agrárias 13: 111-117.

CALDEIRA RM \& VAZ PORTUGAL A. 1998. Condição corporal: conceitos, métodos de avaliação e interesse da sua utilização como indicador na exploração de ovinos. Revista Portuguesa de Ciências Veterinárias 93: 95-102.

COSTA RLD et al. 2007. Desempenho reprodutivo de ovelhas Santa Inês submetidas à amamentação contínua ou controlada. Boletim de Indústria Animal 64: 51-59.

EMEDIATO RMS et al. 2009. Desempenho de ovelhas da raça Bergamácia alimentadas com dieta contendo gordura protegida. Revista Brasileira de Zootecnia 38: 1812-1818. FERNANDES SR et al. 2012. Lipidograma como ferramenta na avaliação do metabolismo energético em ruminantes. Revista Brasileira de Agrociência 18: 21-32.

FUNSTON RN. 2004. Fat supplementation and reproduction in beef females. Journal of Animal Science 82: 154-161.

GRESSLER MAL \& SOUZA MIL. 2009. Efeitos da suplementação com gordura protegida sobre a foliculogênese ovariana de ruminantes. Veterinária e Zootecnia 3: 70-79.

MATTOS R et al. 2000. Effects of dietary fatty acids on reproduction in ruminants. Reviews of Reproduction 5: 3845.

NEGRI R et al. 2014. Desempenho produtivo de ovelhas alimentadas com gordura ruminalmente inerte de óleo de palma no terço final de gestação. In: XXIV Congresso Brasileiro de Zootecnia. Resumos... Vitória: Associação Brasileira de Zootecnistas.

NOGUEIRA DM et al. 2009. Desempenho produtivo e reprodutivo de ovelhas suplementadas com misturas múltiplas contendo diferentes níveis de energia. In: XIX Congresso Brasileiro de Zootecnia. Resumos... Águas de Lindóia: Associação Brasileira de Zootecnistas.

QUEIROZ EO et al. 2015. Parâmetros fisiológicos e desempenho para ovelhas Santa Inês e cordeiros $1 / 2$ Dorper - Santa Inês nas estações verão e inverno. Revista Brasileira de Saúde e Produção Animal 16: 199-209.

RIBEIRO JÚNIOR JI \& MELO ALP. 2009. Guia prático para utilização do SAEG. Viçosa: UFV. 287p.

ROSA GT et al. 2007. Influência da suplementação no pré-parto e da idade de desmama sobre o desempenho de cordeiros terminados em confinamento. Revista Brasileira de Zootecnia 36: 953-959.

SANTOS JEP et al. 2008. Long chain fatty acids of diet as factors influencing reproduction in cattle. Reproduction in Domestic Animals 43: 23-30.

SARTORI R \& GUARDIEIRO MM. 2010. Fatores nutricionais associados à reprodução da fêmea bovina. Revista Brasileira de Zootecnia 39: 422-432.

VALINOTE AC et al. 2006. Fontes de lipídio e monensina sódica na fermentação, cinética e degradabilidade ruminal de bovinos. Pesquisa Agropecuária Brasileira 41: 117-124. 